\title{
The Effect of Cognitive Rehabilitation on Peripheral Blood B Cell Distribution and Specific Gene Expression Levels in MS patients
}

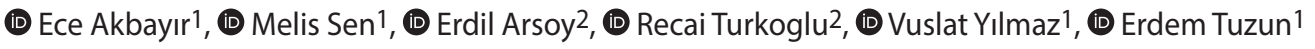 \\ ${ }^{1}$ Istanbul University, Aziz Sancar Institute of Experimental Medicine, Department of Neuroscience, Istanbul, Turkey \\ 2 Haydarpasa Numune Training and Research Hospital, Clinic of Neurology, Istanbul, Turkey
}

\section{Abstract}

Objective: Multiple Sclerosis (MS) is an autoimmune, demyelinating, and neurological disorder of the central nervous system (CNS). For years, cellular immunity is thought to be the possible potential mechanism in the immunopathogenesis of the disease; however, nowadays, studies show that humoral immunity has a major part and also plays an important role. Neuropsychological tests in known to detect mild, moderate, or severe cognitive impairments that occur in patients, particularly memory and executive functions are affected. Studies showed that computer-assisted cognitive rehabilitation (CCR) studies that are performed with special software improve memory functions and change the levels of memory proteins, neurotrophic factors, and neurotransmitters in the peripheral blood.

Materials and Methods: Patients with MS ( $n=18)$ who are included in the study participated in the CCR for 6 months, and blood samples were gathered at the beginning and after the neuro-rehabilitation stage of the study. Flow cytometry is used to immunophenotype the PBMCs. The expression level of B cell-associated genes that were detected by another microarray study was determined by a real-time polymerase chain reaction. The immunophenotype and gene expression levels of the patients and 20 healthy volunteers, from whom only peripheral blood samples were taken, were compared.

Results: After the CCR, non-significant increased natural killer cells were observed. Regulatory B cell percentages were increased following the rehabilitation period, which differed only from healthy donors. The significantly increased transforming growth factor-beta and ATPase Na+/K+ Transporting Subunit Beta 3 gene expressions after rehabilitation was evaluated as a shift of cell activity toward immunosuppression.

Conclusion: The findings suggest that treatment methods, such as cognitive rehabilitation, that are not based on biological foundations may also have molecular and cellular effects. This supports its role in the regression of inflammation and clinical progression.

Keywords: $\mathrm{B}$ lymphocytes, cognitive rehabilitation, gene expression, multiple sclerosis

\section{Introduction}

Multiple sclerosis (MS) is defined as a chronic inflammatory disease of the central nervous system (CNS) that is characterized by demyelination and axonal damage caused by $T$ cells of the adaptive immunity. Cellular immunity is thought to be the most important possible causal mechanism in the immunopathogenesis of MS; however, studies show that humoral immunity also plays a critical role. Particularly, the findings of the studies show that B cells are important in the pathogenesis of MS and the presence of degradation products of plasma cells, myelin-specific antibodies, and possibly complement factors activated by these antibodies, in both chronic MS plaques and acute MS lesions. In addition, the presence of immunoglobulin $\mathrm{G}(\mathrm{lgG})$ and complement deposits, especially in lesion areas with lower myelin destruction, support the assumptions that antibodies are effective in lesion formation.

Other findings showed the active role of $B$ cells in the pathogenesis of the disease, which are intrathecal immunoglobulin production and the presence of oligoclonal bands that are only found in the cerebrospinal fluid (CSF), somatic hypermutation of B cells that are detected in MS lesions and patient CSF samples, plasmapheresis that clears antibodies, and monoclonal antibody treatments, such as rituximab/ocrelizumab targeting B lymphocytes, improve MS

Address for Correspondence: Erdem Tuzun, Istanbul University, Aziz Sancar Institute of Experimental Medicine, Department of Neuroscience, Istanbul, Turkey Phone: +90 2124142000 E-mail: drerdem@yahoo.com ORCID-ID: orcid.org/0000-0002-4483-0394

Received: 20.09.2021 Accepted: 01.12.2021

'Copyright 2021 by the Journal of Multiple Sclerosis Research published by Galenos Publishing House. 
findings. Moreover, a correlation was found between the B cell, plasmablast, and immunoglobulin M levels in the CSF and clinical progression and the number of contrast-enhancing lesions (1-3).

Jean-Martin Charcot, the first neurologist to describe the clinical and pathological characteristics of MS, pointed to cognitive impairments as "significant loss of memory, slowing of cognition, and in their entirety, atrophy of intellectual and emotional abilities" (4). These days, cognitive impairments are seen in $70 \%$ of patients with MS (5). Information processing speed, executive functions, attention, and long-term and working memory deficits are the most common conditions (6). Cognitive rehabilitation is a set of therapeutic activities that have been studied in recent years and are designed to reconsider the individual's memory and other cognitive functions (7). Studies showed that cognitive exercises can lead to a significant increase in attention and thus a reduction in attention-related problems compared to non-specific training (8). Neurobehavioral interventions and methods that applied cognitive rehabilitation had positive effects on the cognitive performance and other connected abilities of patients with MS and have succeeded in increasing the functionality of the individual in daily life (9). The study results, in which Messinis et al. (9) used the RehaCom software, showed and stated that after the treatment in patients with MS have a significantly improved verbal episodic and visuospatial memory, response inhibition, processing speed/working memory, semantic fluency, attention/visual-motor scanning speed, and group switching abilities. Computer-assisted cognitive rehabilitation studies are also known to improve memory functions and change memory proteins, neurotrophic factors, and neurotransmitter levels in the peripheral blood (4-9).

This study aimed to evaluate the possible effect of computerized neurocognitive rehabilitation on the peripheral B cells in patients with MS and investigate the relationship of neurorehabilitation with the clinical presentations of patients.

\section{Materials and Methods}

\section{Study Group}

Patients with MS ( $n=18$, RRMS) who are followed in Haydarpaşa Numune Training and Research Hospital, Neurology Clinic, MS Outpatient Clinic, and age and gender-matched healthy individuals ( $n=20)$ as the control group, were included in the study (project no: HNEAH-KAEK 2016/110). The study group included patients over the age of 18 years who were diagnosed following the revised McDonald criteria of 2017 and did not have an attack in the last 3 months, whereas the healthy control group were those over the age of 18 years who did not have an autoimmune disease, any infectious disease in the last 3 months, and did not use corticosteroids or immunosuppressive drugs. Additionally, none of the patients was in an attack period.
All participants provided written informed consent before the study.

\section{Computer-Assisted Cognitive Rehabilitation}

"NOROSOFT" is software that included mental exercise programs for the computer-assisted cognitive rehabilitation (CCR) method. The program consists of 5 modules: attention, memory, reasoning, visual, and verbal tasks. Volunteer patients were asked to do the application for 50 min, 5 days a week. Sessions had a 20-min daily exercise segment that allowed patients to perform in each module, and 30 min of specific training based on each patient's "Rao's Brief Repeatable Battery of Neuropsychological Tests" scores. Weekly follow-ups of patients were supervised by the institutional interface of the program and were evaluated by a physician monthly. The peripheral blood samples were collected from the study group at the beginning and after 6 months of the CCR. Healthy donors were not included in this program and only peripheral blood samples were obtained.

\section{Isolation of Peripheral Blood Mononuclear Cells (PBMCs) and Immunophenotyping}

Peripheral blood cells of the participants were isolated using the density gradient centrifugation method and frozen at $-80{ }^{\circ} \mathrm{C}$ in $10 \%$ dimethyl sulfoxide and fetal bovine serum. Frozen cells were simultaneously thawed and viability tests with trypan blue were used. Cells were stained with anti-human monoclonal CD19APC, CD24-PerCP, CD138-PE, IgD-APC/Cy7, CD38-Alexafluor 700, CD27-FITC (Biolegend) and Multitest CD3 FITC/16+56 PE/CD45 PerCP/CD19 APC (Becton Dickinson) antibodies for 30 min at 4 ${ }^{\circ} \mathrm{C}$. Cells that are evaluated on the flow cytometer (BD FACS Aria II) were then analyzed by FlowJo software.

\section{Target Genes Identification and RNA Isolation}

Data from our previous microarray study were used to identify candidate genes (10). In that study, RNA expression profiles of PBMCs of 5 RRMS, 6 benign MS, and 5 healthy donors were determined with the Sureprint G3 Human Gene Expression V3 microarray (MA) system. In this context, a total of 26083 Entrez genes were evaluated, and target genes that differed between RRMS and healthy donors were determined. Selected genes and primer sequences are listed in Table 1.

For the validation of the identified candidate genes, RNA isolation from the frozen PBMCs of all cases was performed following the manufacturer's instructions (QIAGEN RNeasy Mini kit, Hilden, Germany). The purity and concentration of the acquired RNA were measured by spectrophotometer. Those with an optical density of 260/280 nm between 1.9 and 2.1 were included in the study.

Real-time Quantitative Polymerase Chain Reaction (qPCR) CDNA synthesis was performed with the Transcriptor First Strand cDNA Synthesis Kit (Basel, Switzerland) following the 


\begin{tabular}{|l|l|l|l|}
\hline \multicolumn{2}{|l}{ Table 1. Identified genes and their primer sequences } & Gene & Primer sequence \\
\hline Gene & Primer sequence & - & - \\
\hline BLK_Frw & TAGATCACAGGGTCGGAAGG & SWAP70_Frw & CGGTGCTGAAGGTTCCTCAT \\
\hline BLK_Rev & GGCAGCGGATCTTATAGTGC & SWAP70_Rev & GACACAGAGGGTCCAACACA \\
\hline TGFB1_Frw & GTACCTGAACCCGTGTTGCT & KCNS3_Frw & AATCGCTACCAGGAACGCAA \\
\hline TGFB1_Rev & CAACTCCGGTGACATCAAAA & KCNS3_Rev & CGATCTCCACTCCTTCCAGC \\
\hline ATP1B3_Frw & CAGTCTGTCCTGATGGAGCA & ACTB_Frw & TGGCACCACACCTTCTACAA \\
\hline ATP1B3_Rev & TGGCACTCCTTCAGGCTTTA & ACTB_Rev & CCAGAGGCGTACAGGGATAG \\
\hline BANK1_Frw & GTTCAGACCCCGCACATATT & HPRT1_Frw & AGTGATGATGAACCAGGTTATGA \\
\hline BANK1_Rev & CCTTCCCCTTCCATTTCATT & HPRT1_Rev & GCTACAATGTGATGGCCTCC \\
\hline BLNK_Frw & GAGCAGTGGTCCGATGACTT & GAPDH_Frw & CCATCAATGACCCCTTCATT \\
\hline BLNK_Rev & TGGGCTTACTGGGAAGTGTC & GAPDH_Rev & TTGACGGTGCCATGGAATTT \\
\hline FCRL2_Frw & CTCTGGGGACTGTTTGGTGT & - \\
\hline FCRL2_Rev & GGTTGGGCTTGAATAGGTGA & \\
\hline
\end{tabular}

instructions of the manufacturer. LightCycler 480 instrument and the Fast Start DNA Master SYBR Green I kit (Roche, Basel, Switzerland) were used for the real-time PCR (RT-PCR) method. The concentrations of the primers were set at 600-800 nM. The glyceraldehyde 3-phosphate dehydrogenase (GAPDH) gene was chosen as a housekeeping gene. After processing, the amplification curves and melting peaks were evaluated.

\section{Statistical Analysis}

The peripheral blood cell subsets were determined by Cell Quest (BD), and FlowJo was used for data analysis. The analysis of variance and Tukey's posthoc test were used for the comparison of more than two groups. Paired t-test was used to compare pre- and post-rehabilitation data. The formula 2-DDCT (DD CT=target gene CT-GAPDH CT) was used to determine the $\mathrm{CT}$ values of target genes and their relative amounts compared to the reference gene, GAPDH, for the relative target gene quantification. Correlation analyzes were performed with the Pearson correlation test. Analyzes were performed on Statistical Package for the Social Sciences 21.0. Graphs were created with the GraphPad Prism 5 and p-values of $<0.05$ were considered statistically significant.

\section{Results}

\section{Clinical and Demographic Data}

All clinical and demographic details of patients with MS $(n=18)$ and healthy participants $(n=20)$ who are included in the study are presented in Table 2. All enrolled participants with MS received immunomodulatory treatment (interferon-beta, fingolimod, or glatiramer acetate).

Patients affected by rehabilitation were also evaluated using neuropsychological test batteries in this study. Our previous study evaluated the effects of computerized rehabilitation on improved executive functions and verbal, visual memory, and motor functions, and the same patients were included in this study.

\begin{tabular}{|l|l|l|}
\hline \multicolumn{3}{|c|}{ Table 2. Clinical and demographic data of the participants } \\
\hline & $\begin{array}{l}\text { Multiple } \\
\text { sclerosis } \\
(\mathrm{n}=18)\end{array}$ & $\begin{array}{l}\text { Healthy } \\
\text { controls } \\
(\mathrm{n}=20)\end{array}$ \\
\hline Sex (F/M) & $12 / 6$ & $12 / 8$ \\
\hline Age (year, mean \pm SD) & $39.6 \pm 11.4$ & $39.3 \pm 8.7$ \\
\hline Disease onset age (year, mean \pm SD) & $28.05 \pm 10.82$ & - \\
\hline Disease duration (year, mean \pm SD) & $10.7 \pm 5.6$ & - \\
\hline Last edss (mean \pm SD) & $2.72 \pm 1.1$ & - \\
\hline Total number of attacks (mean \pm SD) & $7 \pm 4.5$ & - \\
\hline $\begin{array}{l}\text { Annual number of attacks (mean } \pm \\
\text { SD) }\end{array}$ & $0.73 \pm 0.48$ & - \\
\hline
\end{tabular}

SD: Standard deviation, F: Famele, M: Male

\section{Comparison of PBMC Phenotypes}

According to the immunophenotyping results of patients with MS (Table 3), the percentage of CD19-expressing B cells did not differ between the groups, and the percentage of $\mathrm{CD}^{+} \mathrm{T}$ cells were significantly decreased in the groups before $(p<0.01)$ and after the rehabilitation $(p<0.05)$. However, this effect was found to be independent of the rehabilitation effects. The CD3CD $16^{+}{ }^{+}$D56 $6^{+}$natural killer (NK) cells were significantly elevated only in the post-rehabilitation group $(p<0.05)$ compared to healthy individuals. The $\mathrm{CD}^{-} \mathrm{CD} 16^{+} \mathrm{CD} 56^{+} \mathrm{NK}$ cells were found to be significantly higher than the healthy ones only in the post-rehabilitation group $(p<0.05)$. The percentages of $\mathrm{CD}^{+}{ }^{\mathrm{CD}} 16^{+} \mathrm{CD} 56^{+}$NKT cells were similar between the study groups (Figure 1).

The peripheral B cell distribution was not different between the study groups; however, unswitched memory B cells $\left(\mathrm{CD}_{19}{ }^{+} \mathrm{gD}^{+} \mathrm{CD} 27^{+}\right)$displayed lower values in the pre- and post-rehabilitation groups compared with the healthy donors $(p<0.05)$. Switched $\left(C D 19^{+} \lg D^{-}\left(D 27^{+}\right) \quad(p=0.0525)\right.$ memory $B$ cells were found to be significantly lower only in the post-rehabilitation group compared to healthy individuals 


\begin{tabular}{|c|c|c|c|c|c|c|}
\hline & Before CCR & After CCR & Healthy controls & $\begin{array}{l}\text { Before CCR vs. } \\
\text { after CCR }\end{array}$ & $\begin{array}{l}\text { Before CCR vs. } \\
\text { HC }\end{array}$ & $\begin{array}{l}\text { After CCR vs. } \\
\text { HC }\end{array}$ \\
\hline Cell Types & Mean \pm SD & Mean \pm SD & Mean \pm SD & $\mathrm{p}$ & $\mathrm{p}$ & $\mathrm{p}$ \\
\hline CD19+ $\mathrm{B}$ cell & $6.12 \pm 6.63$ & $4.47 \pm 4.69$ & $5.93 \pm 2.86$ & 0.1343 & 0.905 & 0.2541 \\
\hline $\mathrm{CD}^{+} \mathrm{T}$ cell & $65.87 \pm 20.86$ & $59.49 \pm 15.21$ & $79.8 \pm 8.05$ & 0.2313 & 0.0091 & $<0.0001$ \\
\hline NK cell & $19.4 \pm 18.24$ & $23.21 \pm 14.10$ & $11.45 \pm 5.96$ & 0.3385 & 0.0772 & 0.0016 \\
\hline NKT cell & $9.15 \pm 6.10$ & $11.83 \pm 11.98$ & $11.62 \pm 7.04$ & 0.3185 & 0.2575 & 0.9472 \\
\hline Naive B cell & $63.44 \pm 13.02$ & $64.33 \pm 17.53$ & $50.56 \pm 18.51$ & 0.542 & 0.0169 & 0.0269 \\
\hline Immature B cell & $10.23 \pm 7.49$ & $7.58 \pm 4.53$ & $8.88 \pm 8.25$ & 0.08 & 0.6006 & 0.5593 \\
\hline Unswitched Memory B cell & $10.58 \pm 7.70$ & $10.76 \pm 6.84$ & $18.98 \pm 9.83$ & 0.6297 & 0.0084 & 0.0054 \\
\hline Switched Memory B cell & $14.19 \pm 8.53$ & $13.61 \pm 7.07$ & $21.6 \pm 11.65$ & 0.8824 & 0.0369 & 0.0217 \\
\hline Breg cell & $4.63 \pm 5.89$ & $7.63 \pm 5.89$ & $2.86 \pm 2.51$ & 0.1285 & 0.2268 & 0.0094 \\
\hline Plasmablasts & $5.28 \pm 6.36$ & $7.02 \pm 7.12$ & $4.31 \pm 3.36$ & 0.1959 & 0.5531 & 0.1349 \\
\hline BLK expression & $0.19 \pm 0.21$ & $0.12 \pm 0.12$ & $0.52 \pm 0.47$ & 0.3987 & 0.0057 & 0.0039 \\
\hline TGFB expression & $0.35 \pm 0.30$ & $0.53 \pm 0.34$ & $0.55 \pm 0.36$ & 0.0169 & 0.1111 & 0.8814 \\
\hline ATP1B3 expression & $0.95 \pm 0.65$ & $1.16 \pm 0.61$ & $1.14 \pm 0.57$ & 0.0437 & 0.4303 & 0.9488 \\
\hline BANK1 expression & $0.22 \pm 0.22$ & $0.17 \pm 0.18$ & $1.44 \pm 1.42$ & 0.9828 & 0.0002 & 0.0043 \\
\hline SWAP70 expression & $0.81 \pm 0.59$ & $0.68 \pm 0.52$ & $1.38 \pm 1.053$ & 0.2488 & 0.045 & 0.0306 \\
\hline KCNS3 expression & $1.06 \pm 1.26$ & $0.65 \pm 1.12$ & $0.16 \pm 0.31$ & 0.9735 & 0.0588 & 0.2449 \\
\hline FCRL2 expression & $0.18 \pm 0.19$ & $0.074 \pm 0.093$ & $0.34 \pm 0.21$ & 0.2473 & 0.0413 & 0.0004 \\
\hline BLNK expression & $0.34 \pm 0.52$ & $0.13 \pm 0.076$ & $0.50 \pm 0.41$ & 0.1257 & 0.4145 & 0.0025 \\
\hline
\end{tabular}

SD: Standard deviation, CCR: Computer-assisted cognitive rehabilitation, HC: Healthy controls
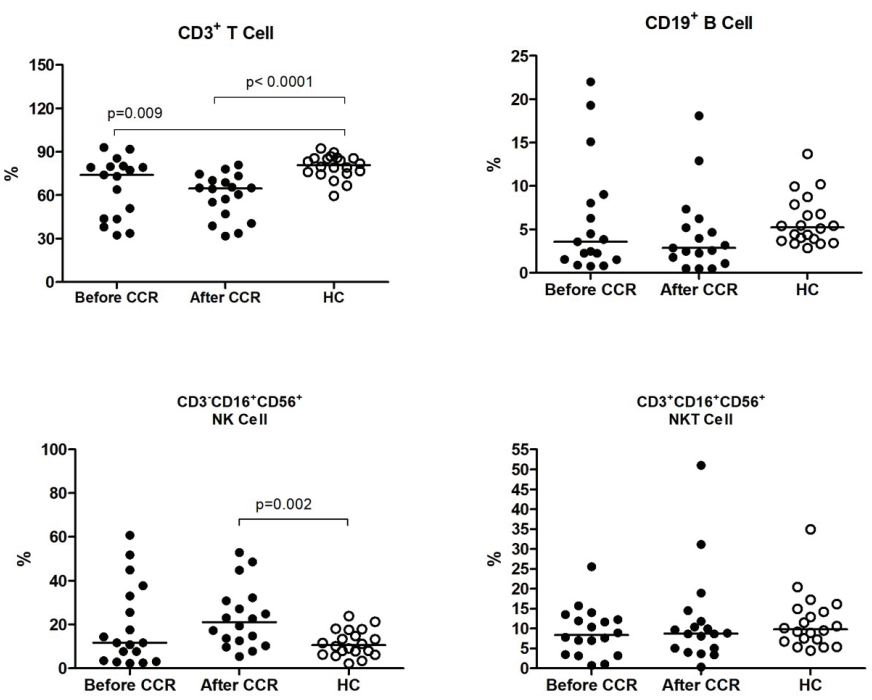

Figure 1. Distribution of peripheral blood $\mathrm{B}, \mathrm{T}$, and natural killer cells (NK and NKT) between the study groups

CCR: Computer-assisted cognitive rehabilitation, HC: Healthy controls

$(p<0.05)$. These results suggest that rehabilitation does not differentiate between these subgroups of $B$ cells. The regulatory B cell (Breg, CD19+CD24++CD38++) subgroup, which has immunosuppressive cell characteristics, was found to increase following the rehabilitation and was remarkably different from the healthy group $(p<0.05)$ (Figure 2).
Plasmablasts $\left(\mathrm{CD} 19^{+} \mathrm{CD} 38^{++} \mathrm{CD} 138^{-}\right)$, which are antibodyproducing cell precursors and antibody-producing plasma cells $\left(\mathrm{CD} 19^{+} \mathrm{CD} 38^{+} \mathrm{CD} 138^{+}\right)$, were determined not different between the study groups. Additionally, the subgroup of regulatory B cells (Breg, CD $19^{+} \mathrm{CD} 24^{++} \mathrm{CD} 38^{++}$) that show immunosuppressive cell characteristics were increased after rehabilitation and this situation differed only from the healthy controls (Figure 2).

\section{Expression Validations of Candidate Genes by RT-PCR}

The expression levels of the genes that are determined from the microarray data analysis were evaluated in the total PBMCs in the blood samples that are gathered from patients with MS before and after the CCR. The gene expression levels of $B L K$, BANK1, SWAP70, and FCRL2 were found to be remarkably lower in patients with MS than in the control groups. However, the CCR did not cause any changes in these gene expressions. No difference was found in transforming growth factor-beta (TGFB) and ATPase Na+/K+ Transporting Subunit Beta 3 (ATP1B3) gene expression between study groups, and the significant increase in expressions ( $p=0.0169$ and $p=0.0437$, respectively) after the CCR was observed. No difference was found between the study groups in the expression levels of KCNS3 and BLNK (Figure 3).

\section{Discussion}

MS is an autoimmune and progressive disorder that develops due to axonal degeneration, demyelination, and inflammation 

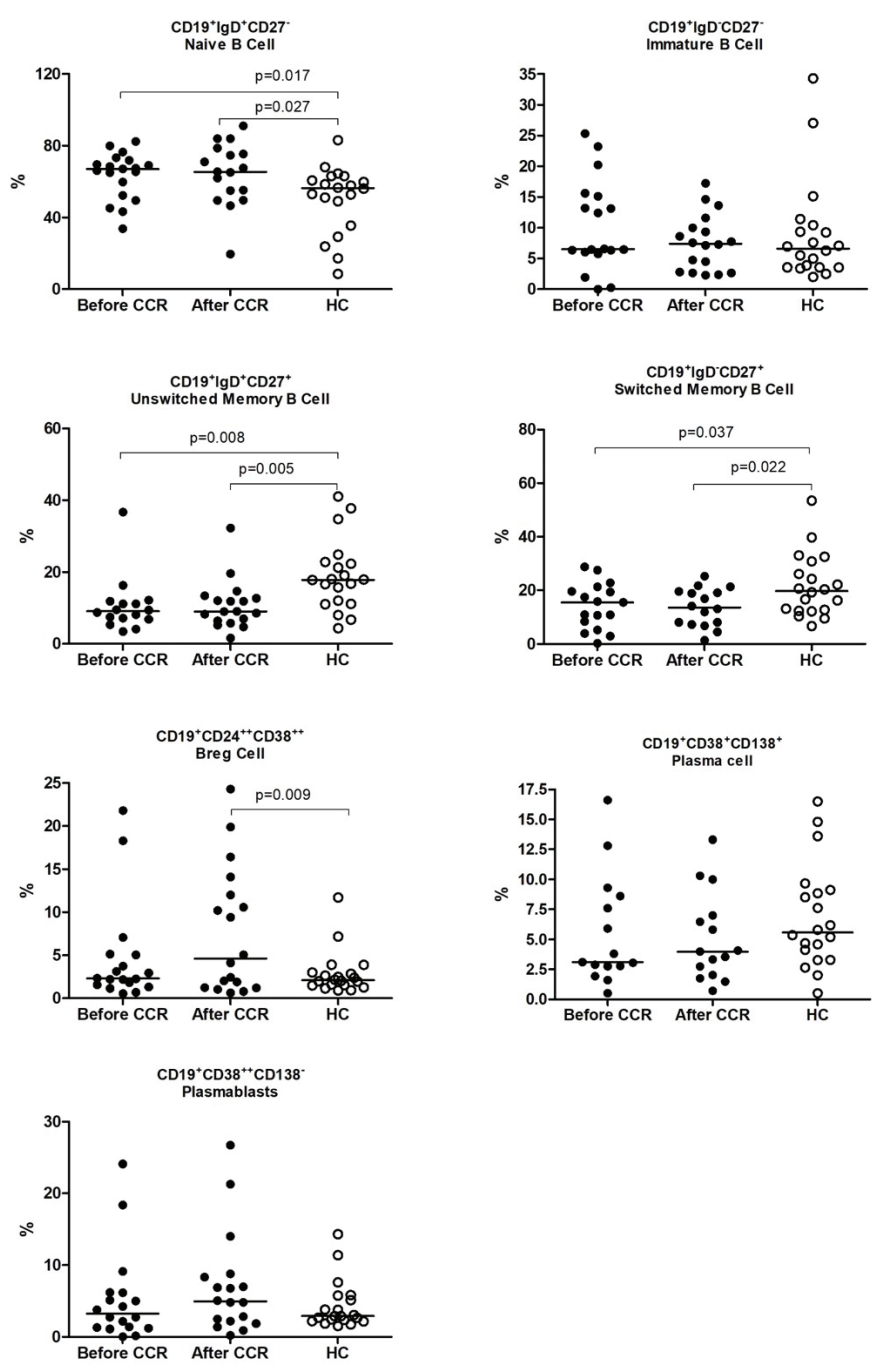

Figure 2. Distribution of peripheral blood B cell subtypes among the study groups

CCR: Computer-assisted cognitive rehabilitation, HC: Healthy controls

and affects the CNS. It is one of the most frequent and most studied neurodegenerative diseases in young adults (11).

The pathological feature of MS include the formation of focal areas of myelin loss in the CNS, called lesions or plaques, and although it spreads to the CNS, the optic nerves, subpial spinal cord, brainstem, cerebellum, and juxtacortical and periventricular white matter regions are primarily affected (12). $T$ cells are known for many years to play an active role in disease pathogenesis. However, in recent years, B cells were determined to be important in the pathogenesis, especially with the role of presenting myelin antigen to $T$ cells, apart from the antibody production.

Optic neuritis is the first attack in $25 \%$ of patients and is associated with conversion to clinically precise MS in 34\%-75\% of patients after 10-15 years from clinical onset (13). Sensory
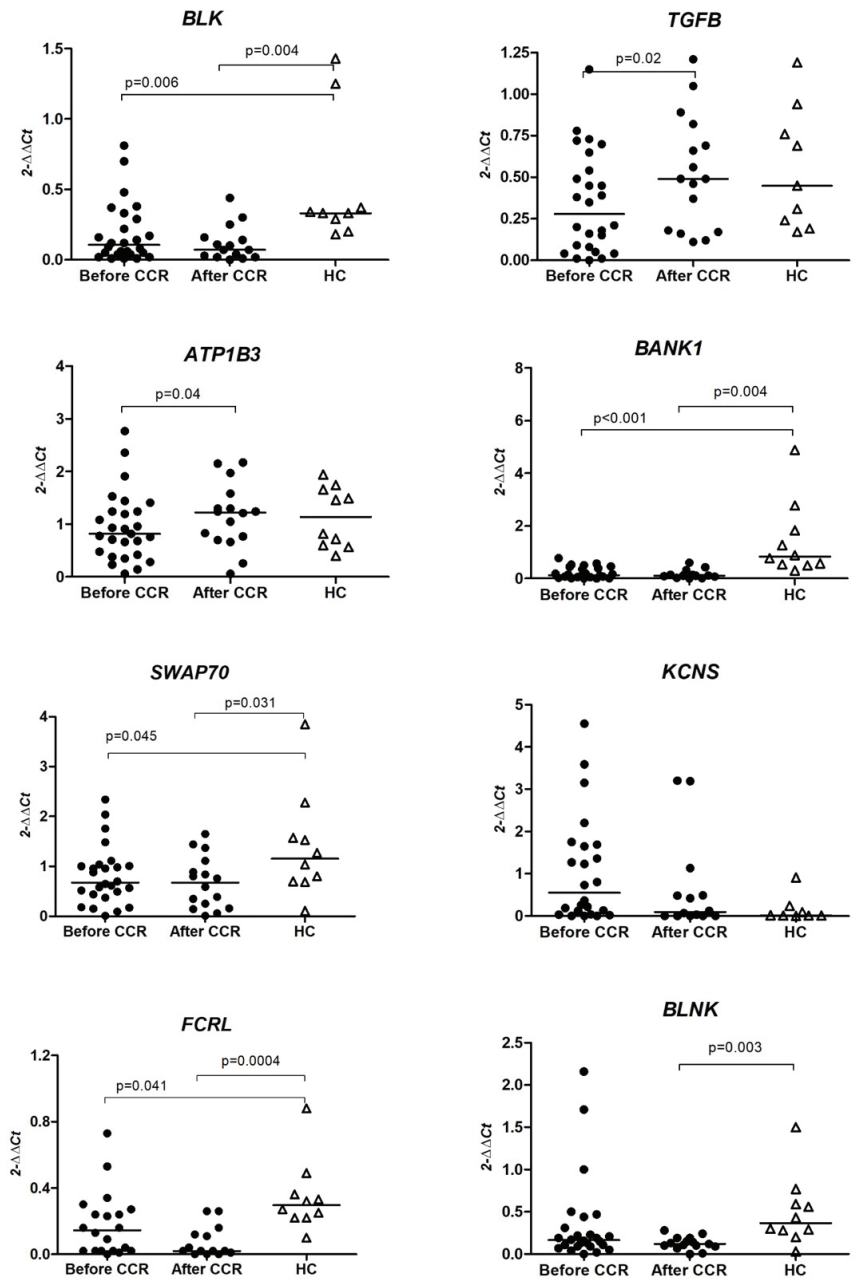

Figure 3. Distribution of relative gene expressions in the study group

CCR: Computer-assisted cognitive rehabilitation, HC: Healthy controls

symptoms that originate from myelitis or brainstem syndromes are the first clinical findings (14). Motor symptoms are the first symptoms of the disease, which affect the majority of patients. However, in addition to these, studies report that $70 \%$ of patients with MS have cognitive impairments (5). The most prevalent cognitive deficits in MS appear to be deficits in information processing speed (6). In addition, the psychological problems of the patients cause more distress than the developing physical symptoms. A positive relationship was stated between the physical disability and the course of depression (15). The effects of rehabilitation in patients were also evaluated using neuropsychological test batteries. Our previous study revealed that improvement in executive functions was determined after computerized rehabilitation while the efficacy of rehabilitation on verbal, visual memory, and motor functions were evaluated, and the same patients were included in this current study (16).

Studies have reported that patients with depression have increased proinflammatory cytokine levels (17). The study 
by Moreira et al. (18) on cognitive behavior therapy (CBT) revealed that CBT is effective for the treatment of depressive manifestations and diminishes levels of Interleukin (IL)- 6 and tumor necrosis factor a in young adults. In the light of these findings, treatments are suggested to have a positive effect on cognition and excluding anti-inflammatory drug therapy or/ and physical rehabilitation may also be beneficial in suppressing the proinflammatory phenotype that predominates in patients with MS. Therefore, anti-inflammatory regulatory B cells (Breg) were determined to increase with neurorehabilitation while proinflammatory effector memory B cells reduce. Moreover, gene expression of $F C R L 2$, which works toward $B$ lymphocyte proliferation, decreased, and the expression of TGFB and ATP1B3 genes, which inhibit B cell proliferation, increased after neurorehabilitation.

Rehabilitation did not affect the distribution of any cells or subgroups; however, cognitive rehabilitation increases Breg cells, which have an anti-inflammatory role in our study. B cells potentiate the immune response in consequence of produced antibodies and activated $T$ cells using antigen presentation. Recent studies show that the suppressive Breg cell group can suppress the inflammatory response with anti-inflammatory cytokines, such as TGF-beta, IL-10, and IL-35. Additionally, Breg cells also control the inflammation by suppressing Th1/Th17 cell differentiation and increasing regulatory $T$ lymphocytes (Treg). Furthermore, decreased Breg levels have been associated with the exacerbation of many neuroimmunological diseases (19). Therefore, the increase in Breg cells suppressed effector T cells and decreased memory B cells.

Patients with MS were determined to have increased NK cells after rehabilitation. Additionally, determining the changes in the NK cell functions after rehabilitation is important since the result will strengthen our finding, which is not included in the literature.

The increasing levels of TGF-beta gene expression, which is known to be produced by Bregs and has a suppressor effect on effector cells, are also consistent with these results. TGF-beta is a cytokine that controls B cell functions and shows this effect by apoptosis in B cells, thereby reducing antibody production and decreasing surface antibody expression of stimulated $B$ cells. The suppression of TGF-beta activity only in B cells led to hyperplasia in lymphatic tissues, an increase in serum Ig levels, and the development of autoantibodies. Emerging findings suggest that TGF-beta is exclusively noteworthy in the control of autoreactive B cells (20). Furthermore, the results indicate that the cognitive improvement that is seen in patients with MS who receive neurorehabilitation therapy may be partially associated with the increased TGF-beta.
The $B$ cell structural protein 1 (BANK1) gene with ankrin repeats, which encodes $B$ cell-specific structural protein, has been associated with autoimmune diseases (21) and shown to negatively affect the CD40-mediated protein kinase B (AKT) pathway, which is part of the dopamine signaling pathway (22). AKT also plays a role in many cellular activities, such as apoptosis, transcription, proliferation, glucose metabolism, and cell migration (21). BLK, one of the tyrosine kinase families, is associated with rheumatoid arthritis and other autoimmune diseases, and the risk alleles identified in the GWAS studies were consistent (22) with reduced levels of BLK gene expression in B cells and B cell lines (23).

Computerized rehabilitation did not cause any changes in $B L K$, BANK1, SWAP70, and FCRL2 gene expressions in our study, which suggests that the percentage of peripheral $B$ cells did not differ between the groups and may suppress the B cell functions, which were related to these genes. Additionally, no difference was found in TGFB1 and ATP1B3 gene expression between the study groups after computer rehabilitation, which can be interpreted as a shift of cell activity toward immune suppression.

The study by Simpfendorfer et al. (24) reported that a low threshold of $B$ cell antigen receptor (BCR) signal and interactions between $B$ cell and $T$ cell play a role in the relationship mechanism between BLK and autoimmune disease. FCRL molecules are described as a new class of molecules that belong to the Ig superfamily with potential activating and inhibitory roles (25). FCRL enhances toll-like receptor-mediated B cell proliferation, activation, and survival via MAPK and NFkB pathways (26). Thus, any change in FCRL expression and its intensity in $B$ cells is thought to be crucial to stabilize $B C R$ signaling and subsequent response of B cell (25). SWAP-70 is defined as a nuclear protein, and its association with $\lg G$ is thought to play a role in faster and stronger signaling of preactivated memory B cells (27). B cell-binding protein (BLNK) acts as a scaffold to assemble molecular complexes, which are involved in signal transduction from the pre-B receptor and the B cell antigen receptor (28). BLNK phosphorylation was shown to elicit different signaling effectors after BCR activation (29). ATP1B3, which is another factor of expression level that is evaluated in our study, is an isoform of Na-K ATPase beta subunit that has been demonstrated to suppress active $B$ lymphocytes and inflammatory NFkB pathway (30). The effect of rehabilitation on gene expression was undetermined, but TGF-beta and ATP1B3, which have a suppressor effect on B cells, was found to increase without reaching significance after neurorehabilitation, and FCRL, which mediates B cell activation, significantly decreases in MS subjects. Suggesting that the B cell changes that are observed in immunophenotyping studies that shift to the anti-inflammatory direction and the accompanying cognitive improvement based on the expression of these B cellspecific genes are also possible. 


\section{Study Limitations}

The limitation of our study includes the number of participants who participated and their follow-ups. Future studies, especially on immunophenotyping and gene expression, should have a sufficient sample size of participants.

\section{Conclusion}

After cognitive rehabilitation in patients MS, anti-inflammatory $B$ cells were increased, the levels of genes that support B cell development decreased, and the genes that suppress B cells increased. These findings support that treatment methods that are not based on biological foundations as cognitive rehabilitation may also have molecular and cellular effects, thus causing regression in inflammation and clinical progression.

\section{Ethics}

Ethics Committee Approval: The study protocol was approved by the Istanbul University, Istanbul Medical Faculty Clinical Research Ethics Committe (date: 27.03.2018 number: 2018/450).

Informed Consent: All subjects provided written informed consent prior to study related procedure.

\section{Authorship Contributions}

Surgical and Medical Practices: E.Ar., R.T., Concept: R.T., V.Y., E.T., Design: R.T., V.Y., E.T., Data Collection or Processing: E.A., M.S., E.Ar., Analysis or Interpretation: V.Y., Literature Search: E.A., V.Y., Writing: E.A., V.Y., E.T.

Conflict of Interest: No conflict of interest was declared by the authors.

Financial Disclosure: Our research was supported by Istanbul University Scientific Research Projects Coordination Unit (project no: TYL-2018-30783).

\section{References}

1. von Essen MR, Ammitzbøll C, Hansen RH, Petersen ERS, McWilliam O, Marquart HV, Damm P, Sellebjerg F. Proinflammatory CD20+ T cells in the pathogenesis of multiple sclerosis. Brain 2019;142:120-132.

2. Reich DS, Lucchinetti CF, Calabresi PA. Multiple sclerosis. N Engl J Med 2018:378:169-180.

3. Lucchinetti C, Brück W, Parisi J, Scheithauer B, Rodriguez M, Lassmann $\mathrm{H}$. Heterogeneity of multiple sclerosis lesions: implications for the pathogenesis of demyelination. Ann Neurol 2000;47:707-717.

4. Maloni, H. Cognitive impairment in multiple sclerosis. J. Nurse Pract 2018;14:172-177.

5. Charvet LE, Yang J, Shaw MT, Sherman K, Haider L, Xu J, Krupp LB. Cognitive function in multiple sclerosis improves with telerehabilitation: Results from a randomized controlled trial. PLoS One 2017;12:e0177177. doi: 10.1371/ journal.pone.0177177. Erratum in: PLoS One 2018;13:e0192317.

6. Chiaravalloti ND, Genova HM, DeLuca J. Cognitive rehabilitation in multiple sclerosis: the role of plasticity. Front Neurol 2015;6:67.

7. Cicerone KD, Dahlberg C, Malec JF, Langenbahn DM, Felicetti T, Kneipp S, Ellmo W, Kalmar K, Giacino JT, Harley JP, Laatsch L, Morse PA, Catanese J. Evidence-based cognitive rehabilitation: updated review of the literature from 1998 through 2002. Arch Phys Med Rehabil 2005;86:1681-1692.
8. Kesselring J, Beer S. Symptomatic therapy and neurorehabilitation in multiple sclerosis. Lancet Neurol 2005;4:643-652.

9. Messinis L, Nasios G, Kosmidis MH, Zampakis P, Malefaki S, Ntoskou K, Nousia A, Bakirtzis C, Grigoriadis N, Gourzis P, Papathanasopoulos P. Efficacy of a computer-assisted cognitive rehabilitation intervention in relapsingremitting multiple sclerosis patients: a multicenter randomized controlled trial. Behav Neurol 2017;2017:5919841.

10. Turkoglu R, Yilmaz V, Ozdemir O, Akbayir E, Benbir G, Arsoy E, Sen M, Ulusoy C, Ozyurt S, Balic N, Sanli E, Kucukali Cl, Karadeniz D, Tuzun E. Peripheral blood $B$ cell subset ratios and expression levels of $B$ cell-associated genes are altered in benign multiple sclerosis. Mult Scler Relat Disord 2021;52:103019.

11. Sakkas GK, Giannaki CD, Karatzaferi C, Manconi M. Sleep Abnormalities in Multiple Sclerosis. Curr Treat Options Neurol 2019;21:4.

12. Popescu BF, Lucchinetti CF. Pathology of demyelinating diseases. Annu Rev Pathol 2012;7:185-217.

13. Filippi M, Bar-Or A, Piehl F, Preziosa P, Solari A, Vukusic S, Rocca MA. Multiple sclerosis. Nat Rev Dis Primers 2018:4:43. Erratum in: Nat Rev Dis Primers 2018;4:49.

14. Rae-Grant AD, Eckert NJ, Bartz S, Reed JF. Sensory symptoms of multiple sclerosis: a hidden reservoir of morbidity. Mult Scler 1999;5:179-183.

15. Mclvor GP, Riklan M, Reznikoff M. Depression in multiple sclerosis as a function of length and severity of illness, age, remissions, and perceived social support. J Clin Psychol 1984;40:1028-1033.

16. Arsoy E, Tuzun E, Turkoglu R. Effects of computer-assisted cognitive rehabilitation in benign multiple sclerosis. Turk J Med Sci 2018;48:999-1005.

17. Munzer A, Sack U, Mergl R, Schönherr J, Petersein C, Bartsch S, Kirkby KC, Bauer K, Himmerich $\mathrm{H}$. Impact of antidepressants on cytokine production of depressed patients in vitro. Toxins (Basel) 2013;5:2227-22240.

18. Moreira FP, Cardoso Tde A, Mondin TC, Souza LD, Silva R, Jansen K, Oses JP, Wiener CD. The effect of proinflammatory cytokines in Cognitive Behavioral Therapy. J Neuroimmunol 2015;285:143-146.

19. Han J, Sun L, Fan X, Wang Z, Cheng Y, Zhu J, Jin T. Role of regulatory b cells in neuroimmunologic disorders. J Neurosci Res 2016;94:693-701.

20. Fujio K, Komai T, Inoue M, Morita K, Okamura T, Yamamoto K. Revisiting the regulatory roles of the TGF- $\beta$ family of cytokines. Autoimmun Rev 2016;15:917-922.

21. Blokland GAM, Wallace AK, Hansell NK, Thompson PM, Hickie IB, Montgomery GW, Martin NG, McMahon KL, de Zubicaray Gl, Wright MJ. Genome-wide association study of working memory brain activation. Int J Psychophysiol 2017; 115: 98-111.

22. Simpfendorfer KR, Olsson LM, Manjarrez Orduño N, Khalili H, Simeone AM, Katz MS, Lee AT, Diamond B, Gregersen PK. The autoimmunity-associated BLK haplotype exhibits cis-regulatory effects on mRNA and protein expression that are prominently observed in B cells early in development. Hum Mol Genet 2012;21:3918-3925.

23. Guthridge JM, Lu R, Sun H, Sun C, Wiley GB, Dominguez N, Macwana SR, Lessard CJ, Kim-Howard X, Cobb BL, Kaufman KM, Kelly JA, Langefeld CD, Adler AJ, Harley IT, Merrill JT, Gilkeson GS, Kamen DL, Niewold TB, Brown EE, Edberg JC, Petri MA, Ramsey-Goldman R, Reveille JD, Vilá LM, Kimberly RP, Freedman BI, Stevens AM, Boackle SA, Criswell LA, Vyse TJ, Behrens TW, Jacob CO, Alarcón-Riquelme ME, Sivils KL, Choi J, Joo YB, Bang SY, Lee HS, Bae SC, Shen N, Qian X, Tsao BP, Scofield RH, Harley JB, Webb CF, Wakeland EK, James JA, Nath SK, Graham RR, Gaffney PM. Two functional lupusassociated BLK promoter variants control cell-type- and developmentalstage-specific transcription. Am J Hum Genet 2014; 94: 586-598.

24. Simpfendorfer KR, Armstead BE, Shih A, Li W, Curran M, Manjarrez-Orduño N, Lee AT, Diamond B, Gregersen PK. Autoimmune disease-associated haplotypes of BLK exhibit lowered thresholds for B cell activation and expansion of Ig class-switched B cells. Arthritis Rheumatol 2015;67:28662876.

25. Rostamzadeh D, Dabbaghmanesh MH, Shabani M, Hosseini A, Amirghofran Z. Expression Profile of Human Fc Receptor-Like 1, 2, and 4 Molecules in 
Peripheral Blood Mononuclear Cells of Patients with Hashimoto's Thyroiditis and Graves' Disease. Horm Metab Res 2015;47:693-698.

26. Li FJ, Schreeder DM, Li R, Wu J, Davis RS. FCRL3 promotes TLR9-induced B-cell activation and suppresses plasma cell differentiation. Eur J Immunol 2013;43:2980-2892.

27. Masat L, Caldwell J, Armstrong R, Khoshnevisan H, Jessberger R, Herndier B, Wabl M, Ferrick D. Association of SWAP-70 with the B cell antigen receptor complex. Proc Natl Acad Sci U S A 2000;97:2180-2184.

28. Kamino H, Futamura M, Nakamura Y, Kitamura N, Kabu K, Arakawa H. B-cell linker protein prevents aneuploidy by inhibiting cytokinesis. Cancer Sci 2008;99:2444-2454.
29. Chiu CW, Dalton M, Ishiai M, Kurosaki T, Chan AC. BLNK: molecular scaffolding through 'cis'-mediated organization of signaling proteins. EMBO J 2002;21:6461-6472.

30. Nishitsuji H, Sugiyama R, Abe M, Takaku H. ATP1B3 Protein Modulates the Restriction of HIV-1 Production and Nuclear Factor k Light Chain Enhancer of Activated B Cells (NF-kB) Activation by BST-2. J Biol Chem 2016;291:47544762. 